\title{
The Puzzling Convergence in Foreign Exchange Volatility
}

\author{
Christopher J. Neely
}

$\mathrm{V}$ olatility in foreign exchange markets reflects uncertainty about economic and financial conditions, such as relative inflation, growth, and employment, which, in turn, reflect changes in tastes, technology, policies, and demographics. Higher volatility increases risk in international trade and financial transactions and raises the cost of hedging that risk.

Foreign exchange, equity, and interest rate volatilities are now relatively stable, declining from the unusually high levels of 19972003 (which saw the Asian currency crisis of 1997, the Russian default of 1998, the Y2K episode, and the September 11th attacks). ${ }^{1}$

There has been another notable trend since 2003: The volatilities of exchange rates have been converging. The top panel of the chart shows this convergence for six exchange rates in one-month implied volatility (IV) - an option-derived measure of the expected size of changes in the exchange rate. The bottom panel shows that the standard deviation between these IVs has declined and has remained low for some time (i.e., the six volatilities are unusually close together).

Why are volatilities converging? Presumably, both common global factors and idiosyncratic factors influence exchange rate volatility. A decline in the importance of idiosyncratic factors would explain the tendency of IVs to move more closely together, but there is no readily apparent reason for such a decline.

One can rule out some potential explanations for the convergence in volatilities, however.

The use of option-derived measures of volatility does not explain the convergence. IVs closely mirror trends in exchange rate historical volatilities, which also exhibit convergence across exchange rates.

The recent decline in average volatility does not explain the convergence in volatilities. While foreign exchange and equity volatilities have declined from the high levels of 1997-2002, they are not unusually low by historical measures. Further, rising volatility from "low volatility" exchange rates, like the CAD/USD and GBP/USD, has contributed to the convergence of volatilities.

The recent trend toward more stable and transparent macroeconomic policies, such as independent central banks and inflation targeting, would tend to lower exchange rate volatilities, but it is unclear how such innovations would produce convergence in volatilities.
Have new foreign exchange intervention policies produced the coherence in IVs? There has been a trend away from intervention in major economies, but such policies predate the convergence of volatilities. The Bank of England, for instance, has not intervened since 1993; the Swiss National Bank and the Bundesbank have not intervened since 1995; U.S. authorities have intervened only twice since 1995; the Bank of Japan has not intervened since March 2004; and the Bank of Canada has not intervened in the CAD/USD market since September 1998. It is difficult to see how such changes could drive the convergence in IVs.

It is possible that international financial integration and the growth of currency markets has helped to stabilize exchange market volatility. But what mechanism would create convergence in volatilities?

The convergence in exchange rate volatilities is a puzzle.

${ }^{1}$ See, e.g., "Recent Volatility Trends in the Foreign Exchange Market," speech by Dino Kos, Federal Reserve Bank of New York, May 11, 2006.

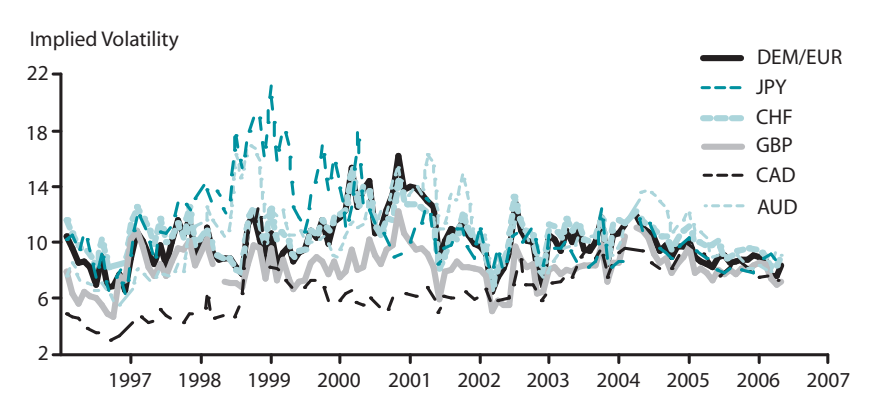

Standard Deviation Across Exchange Rates

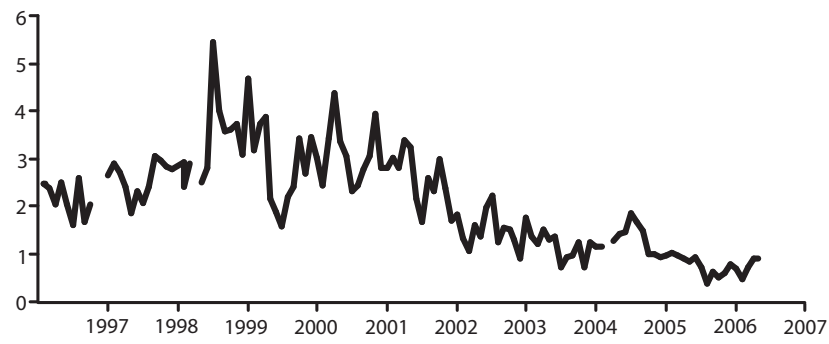

NOTE: Monthly implied foreign exchange volatility from 1996-2006:06. The exchange rates involve the following currencies against the U.S. dollar: Deutsche mark (DEM)/Euro (EUR), Japanese yen (JPY), Swiss franc (CHF), British pound (GBP), Canadian dollar (CAD), and Australian dollar (AUD). 